\title{
Combination therapy based on the angiotensin receptor blocker olmesartan for vascular protection in spontaneously hypertensive rats
}

\author{
NARUYA TOMITA $^{1}$, KEITA YAMASAKI ${ }^{2}$, MARIANA K. OSAKO ${ }^{2}$, NORIO KOMAI ${ }^{1}$, \\ TAKASHI SHIMOSATO ${ }^{3}$ and RYUICHI MORISHITA ${ }^{2}$ \\ ${ }^{1}$ Division of Nephrology, Department of Internal Medicine, Kawasaki Medical School, Kurashiki 701-0192; \\ ${ }^{2}$ Division of Clinical Gene Therapy, Osaka University Graduate School of Medicine, \\ Suita 565-0871; ${ }^{3}$ Nissei Bilis Co., Ltd., Shiga 520-0052, Japan
}

Received March 31, 2009; Accepted June 25, 2009

DOI: $10.3892 / \mathrm{mmr} 00000164$

\begin{abstract}
For hypertension, combination therapies are recommended to acheive a low target blood pressure. In this study, the efficacy of combination therapies for preventing organ damage was investigated in spontaneously hypertensive rats (SHR). Twenty-week-old male SHR were orally administered olmesartan (Olm) (5 mg/kg/day) for the first 4 weeks. Subsequently, rats were randomly divided into 5 groups and administered add-on drugs for another 4 weeks as follows: $\mathrm{Olm}+\mathrm{Olm}(5 \mathrm{mg} / \mathrm{kg} /$ day), Olm+azelnidipine (Aze) $(30 \mathrm{mg} / \mathrm{kg} /$ day), Olm+temocapril (Tem) (10 mg/kg/day), Olm+atenolol (Ate) (5 mg/kg/day), Olm+hydrochlorothiazide (HCTZ) $(5 \mathrm{mg} / \mathrm{kg} /$ day). Blood pressure and heart rate were measured at weeks 0 , 4 and 8 by the tail-cuff method. Heart and kidney weights were determined, and endothelial function was assessed by evaluating the dilator response to acetylcholine. In comparison to untreated control SHR, a significant reduction in systolic blood pressure was observed at weeks 4 and 8 in all groups $(\mathrm{p}<0.05)$, while heart rate was significantly reduced at week 8 in only the Olm+Aze and Olm+Ate groups $(\mathrm{p}<0.05)$. In all groups, heart but not kidney weight was significantly decreased $(\mathrm{p}<0.05)$, and endothelial function was significantly improved $(\mathrm{p}<0.05)$ compared to the control SHR. In the Olm+Olm, $\mathrm{Olm}+\mathrm{Tem}$ and $\mathrm{Olm}+\mathrm{Aze}$ groups, endothelial function was significantly improved as compared to the other treatment groups $(\mathrm{p}<0.05)$. Thus, when using an angiotensin receptor blocker as a first-line therapy, an antihypertensive in the form of an angiotensin-converting enzyme inhibitor, angiotensin receptor blocker, or calcium channel blocker, such as azelnid-
\end{abstract}

Correspondence to: Dr Naruya Tomita, Division of Nephrology, Department of Internal Medicine, Kawasaki Medical School, 577 Matsushima, Kurashiki 701-0192, Japan

E-mail: tomita@med.kawasaki-m.ac.jp

Key words: angiotensin receptor, olmesartan, spontaneously hypertensive rats ipine, should be used as a second-line drug to protect against vascular damage.

\section{Introduction}

Data from the largest meta-analysis of hypertensive patients conducted to date clearly indicate that increased systolic blood pressure (BP) in any age group is associated with a significant increase in cardiovascular disease (1). Several studies have confirmed the significant cardiovascular risk associated with hypertension, and the impressive health benefits that can be derived from treatment of this disease (2). Despite these findings, worldwide epidemiological data show that less than one-third of hypertensive patients achieve a BP $<140 / 90 \mathrm{mmHg}$ (3). Notably, among patients receiving antihypertensive medication and follow-ups by a physician, less than $50 \%$ have a BP $<140 / 90 \mathrm{mmHg}(4,5)$.

Angiotensin-converting enzyme (ACE) inhibitors, angiotensin receptor blockers (ARBs) and long-acting calcium channel blockers (CCBs) are widely recognized as the most effective drugs for the treatment of hypertension. Recently published clinical trials, such as CASE-J and VALUE, suggest that an ARB is best used as the first-line drug to achieve a low target $\mathrm{BP}$ in patients with diabetes, ischemic heart disease or chronic kidney disease $(3,6,7)$.

The importance of combination therapy in the treatment of hypertension is well established. Clinically, combination therapy for hypertension using two or more drugs from different classes can result in improved drug efficacy $(3,8)$. However, it remains to be determined which drugs are most effective when used as second-line therapy to protect against the organ damage induced by hypertension. In particular, the combination of a $\mathrm{CCB}$ and either an ACE inhibitor or an ARB is popular in the treatment of hypertension. On the other hand, diuretics have been established worldwide as potent hypertensive drugs. In this study, we compared the efficacy of various ARB-based combination therapies (ARB/ARB, ARB/ACE inhibitor, ARB/ $\mathrm{CCB}, \mathrm{ARB} / \beta$-blocker and $\mathrm{ARB} /$ diuretic) in spontaneously hypertensive rats (SHR) by measuring heart and kidney weights and assessing endothelial function in the aorta. 


\section{Materials and methods}

Experimental design. Male SHR (15 weeks old) were purchased from Charles River Breeding Laboratories (Osaka, Japan). The rats were given free access to water and standard laboratory rat chow $(11.3 \mathrm{mEq} \mathrm{Na} / 100 \mathrm{~g}, 32.6 \mathrm{mEq} \mathrm{K}+100 \mathrm{~g}$, $24.6 \%$ protein by weight; Oriental Yeast Co., Osaka, Japan), and were maintained in a 12-h light to 12-h dark photoperiod. Rats were divided into an untreated control group and 5 groups treated for 4 weeks with olmesartan (Olm). Subsequently, Olm treatment was continued in the treatment groups for another 4 weeks with the addition of i) Olm, ii) temocapril (Tem), iii) azelnidipine (Aze), iv) atenolol (Ate) or v) hydrochlorothiazide (HCTZ). Drugs were administered by gavage. After a total treatment period of 8 weeks, the rats were sacrificed by decapitation, and the hearts and kidneys were harvested and weighed. The experimental protocol of the study was approved by the Osaka University Ethics Committee of Animal Experiments.

Drugs. Olm, Tem and Aze were obtained from Daiichi-Sankyo Co. Ltd. (Tokyo, Japan). Ate and HCTZ were purchased from Sigma Chemical Co. (St. Louis, MO).

Measurement of body weight, blood pressure and heart rate. At weeks 0, 4 and 8, body weight (BW) was measured. Systolic $\mathrm{BP}$ and heart rate (HR) were also measured at weeks 0, 4 and 8 using the tail-cuff method in conscious rats with a sphygmomanometer (Softron Co. Ltd., Tokyo, Japan) as previously described (9).

Evaluation of vasodilator properties in response to acetylcholine. Freshly harvested aortas were cleaned of fat and connective tissues, cut into helical strips and mounted in 30-ml organ baths containing Krebs-Henseleit buffer $(120 \mathrm{mM} \mathrm{NaCl}$, $4.7 \mathrm{mM} \mathrm{KCl}, 2.5 \mathrm{mM} \mathrm{CaCl}_{2}, 1.2 \mathrm{mM} \mathrm{MgSO}_{4}, 1.2 \mathrm{mM} \mathrm{KH}_{2} \mathrm{PO}_{4}$, $25 \mathrm{mM} \mathrm{NaHCO}_{3}, 5.5 \mathrm{mM}$ glucose, $\mathrm{pH}$ 7.4), then maintained at $37^{\circ} \mathrm{C}$ and oxygenated with $95 \% \mathrm{O}_{2}, 5 \% \mathrm{CO}_{2}(10-12)$. Vessels were equilibrated for $60 \mathrm{~min}$ with changes in the bathing fluid every $15 \mathrm{~min}$. Isometric tension studies were performed using a Grass model 7D polygraph. Optimal resting tension was determined in baseline studies, then the response to vasoactive drugs was determined as previously described (10-12). Cumulative dose-response curves to phenylephrine $\left(10^{-9}\right.$ to $10^{-4} \mathrm{M}$ ) were established. The vessels were then submaximally pre-contracted with phenylephrine (typically $3 \times 10^{-6} \mathrm{M}$ ), and endothelial function was evaluated by means of vascular relaxation to acetylcholine $\left(10^{-9}\right.$ to $\left.10^{-4} \mathrm{M}\right)$. Nitric oxide mediation of acetylcholine responses was confirmed by blocking acetylcholine-induced relaxation using $\mathrm{N} \omega$-nitro-Larginine methyl ester (L-NAME) (1 mM), a specific competitive inhibitor of nitric oxide synthase. Contractile responses were measured from the polygraph chart and expressed as a percentage of the maximal contraction, and relaxation was expressed as a percentage of the precontracted tension.

Statistical analysis. All values are expressed as the mean \pm SEM. Analysis of variance followed by the Bonferroni/ Dunnet's test was employed to determine the significance of differences in multiple comparisons. P-values $<0.05$ were considered statistically significant.
Table I. Changes in body weight (g).

\begin{tabular}{lccc}
\hline Group & Week 0 & Week 4 & Week 8 \\
\hline WKY & $351.2 \pm 4.2$ & $385.9 \pm 6.1$ & $417.2 \pm 6.6$ \\
SHR & $358.9 \pm 5.6$ & $392.3 \pm 6.3$ & $409.2 \pm 7.3$ \\
Olm+Olm & $363.0 \pm 2.5$ & $391.6 \pm 3.3$ & $404.2 \pm 3.6$ \\
Olm+Aze & $357.8 \pm 5.3$ & $388.4 \pm 5.1$ & $400.1 \pm 5.7$ \\
Olm+Tem & $352.1 \pm 5.8$ & $382.3 \pm 5.6$ & $398.5 \pm 5.9$ \\
Olm+Ate & $362.6 \pm 2.8$ & $394.0 \pm 3.7$ & $401.1 \pm 4.2$ \\
Olm+HCTZ & $356.6 \pm 5.0$ & $388.2 \pm 5.1$ & $387.6 \pm 5.7$ \\
\hline
\end{tabular}

Measurements were taken at week 0 (before the start of treatment) and at weeks 4 and 8 after the start of treatment. WKY, untreated Wistar Kyoto rats; SHR, untreated spontaneously hypertensive rats; Olm, olmesartan; Aze, azelnidipine; Tem, temocapril; Ate, atenolol; HCTZ, hydrochloro-thiazide. $n=8$ per group. Values are the mean \pm SE.

Table II. Changes in systolic blood pressure (mmHg).

\begin{tabular}{lccc}
\hline Group & Week 0 & Week 4 & Week 8 \\
\hline WKY & $115 \pm 2$ & $114 \pm 1$ & $114 \pm 1$ \\
SHR & $211 \pm 3$ & $211 \pm 2$ & $215 \pm 2$ \\
Olm+Olm & $210 \pm 3$ & $194 \pm 2$ & $183 \pm 2$ \\
Olm+Aze & $210 \pm 3$ & $194 \pm 1$ & $180 \pm 1$ \\
Olm+Tem & $210 \pm 3$ & $193 \pm 1$ & $177 \pm 1$ \\
Olm+Ate & $210 \pm 3$ & $191 \pm 2$ & $180 \pm 1$ \\
Olm+HCTZ & $211 \pm 3$ & $193 \pm 2$ & $174 \pm 2$ \\
\hline
\end{tabular}

Measurements were taken at week 0 (before the start of treatment) and at weeks 4 and 8 after the start of treatment. WKY, untreated Wistar Kyoto rats; SHR, untreated spontaneously hypertensive rats; Olm, olmesartan; Aze, azelnidipine; Tem, temocapril; Ate, atenolol; HCTZ, hydrochlorothiazide. $n=8$ per group. Values are the mean \pm SE.

\section{Results}

Body weight, blood pressure and heart rate. Table I shows the changes in BW. None of the treatments affected BW, as no significant differences were observed when comparing the BW of the treatment groups. Table II shows the changes in systolic BP. In all the treated groups, there were significant reductions in BP at 4 weeks after treatment with olmesartan. At week 8, a further significant reduction in BP was observed. There were no significant differences between the groups at weeks 4 or 8 . Table III shows the changes in HR. No significant changes were observed among the treated groups at week 4. However, at week 8 , HR was significantly reduced in the $\mathrm{Olm}+\mathrm{Aze}$ and $\mathrm{Olm}+$ Ate groups compared to untreated control SHR $(\mathrm{p}<0.05)$.

Effect on cardiac and kidney weights. Fig. 1 shows heart and left ventricle (LV) weights corrected for BW in SHR after 8 weeks of treatment. The corrected heart and LV weights were significantly decreased by each treatment compared to 
Table III. Changes in heart rate (beats/min).

\begin{tabular}{lccc}
\hline Group & Week 0 & Week 4 & Week 8 \\
\hline WKY & $394 \pm 8$ & $382 \pm 8$ & $376 \pm 8$ \\
SHR & $385 \pm 5$ & $381 \pm 72$ & $377 \pm 5$ \\
Olm+Olm & $409 \pm 6$ & $396 \pm 5$ & $394 \pm 5$ \\
Olm+Aze & $400 \pm 7$ & $392 \pm 10$ & $373 \pm 8$ \\
Olm+Tem & $393 \pm 12$ & $3943 \pm 10$ & $388 \pm 9$ \\
Olm+Ate & $395 \pm 11$ & $385 \pm 8$ & $364 \pm 8$ \\
Olm+HCTZ & $396 \pm 9$ & $375 \pm 9$ & $381 \pm 7$ \\
\hline
\end{tabular}

Measurements were taken at week 0 (before the start of treatment) and at weeks 4 and 8 after the start of treatment. WKY, untreated Wistar Kyoto rats; SHR, untreated spontaneously hypertensive rats; Olm, olmesartan; Aze, azelnidipine; Tem, temocapril; Ate, atenolol; HCTZ, hydrochlorothiazide. $n=8$ per group. Values are the mean \pm SE.

the heart and LV weights of the control SHR. The corrected heart and LV weights of the control SHR were significantly increased compared to those of untreated Wistar Kyoto (WKY) rats, consistent with previous reports (10). Among the treatment groups, there were no significant differences between the corrected heart and LV weights.

As shown in Fig. 2, the corrected kidney weight to BW of the SHR was significantly increased compared to that of the WKY rats. None of the treatments had an effect on kidney weight, as no significant differences were observed when comparing the corrected kidney weights of the treatment groups.

Effect on endothelial function. It is known that hypertension induces the impairment of endothelial function. In animal models, this is commonly assessed by the dilator response to acetylcholine. As previously reported, the dilator response of the aorta in the SHR was impaired compared to that observed in WKY control rats (10). Antihypertensive treatments are known to improve impaired endothelial function. There were significant improvements in impaired endothelial function in all the treatment groups of the present study (Fig. 3A). Strong inhibition of the renin-angiotensin system (RAS) by $\mathrm{Olm}+\mathrm{Olm}$ and Olm+Tem resulted in increased improvement of endothelial function as compared to the groups administered a $\beta$-blocker or diuretic as the second-line therapy. Notably, the Olm+Aze group showed almost the same improvement in endothelial function as the Olm+Olm and Olm+Tem groups. Moreover, acetylcholine at a concentration of $10^{-6.5} \mathrm{M}$ resulted in a significant improvement in impaired endothelial function in the $\mathrm{Olm}+\mathrm{Olm}, \mathrm{Olm}+\mathrm{Aze}$ and $\mathrm{Olm}+\mathrm{Tem}$ groups compared to the Olm+Ate and Olm+HCTZ groups $(\mathrm{p}<0.05)$ (Fig. 3B). The endothelium-dependent dilatation of the aorta in the SHR treated with each drug was consistent with the finding that this increase in dilation was completely abolished by the administration of L-NAME (data not shown). The endotheliumdependent dilation of the aorta in untreated control SHR was also completely abolished by the administration of L-NAME (data not shown).
A.

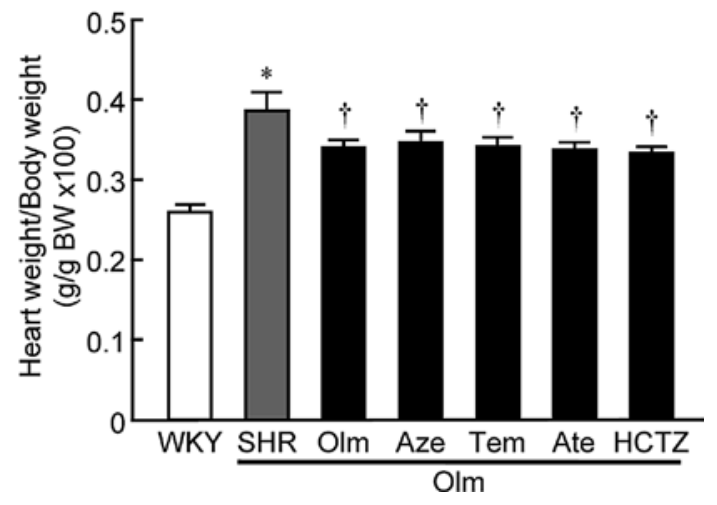

B.

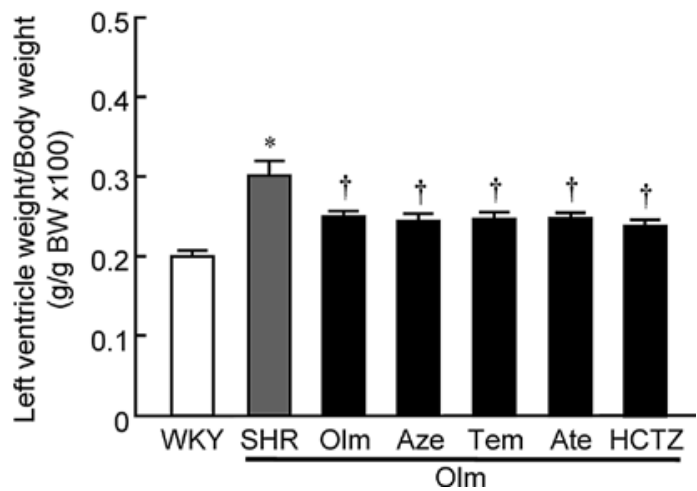

Figure 1. Protective effect of olmesartan (Olm), azelnidipine (Aze), temocapril (Tem), atenolol (Ate) and hydrochlorothiazide (HCTZ) on cardiac hypertrophy. Cardiac hypertrophy in spontaneously hypertensive rats was assessed by measuring the heart and left ventricular weights. Values are the mean $\pm \mathrm{SE}$ of 6 animals, expressed as the ratio of heart weight (A) and left ventricle weight (B) to body weight. " $\mathrm{p}<0.01$ and ${ }^{\dagger} \mathrm{p}<0.05$ vs. untreated Wistar Kyoto rats.

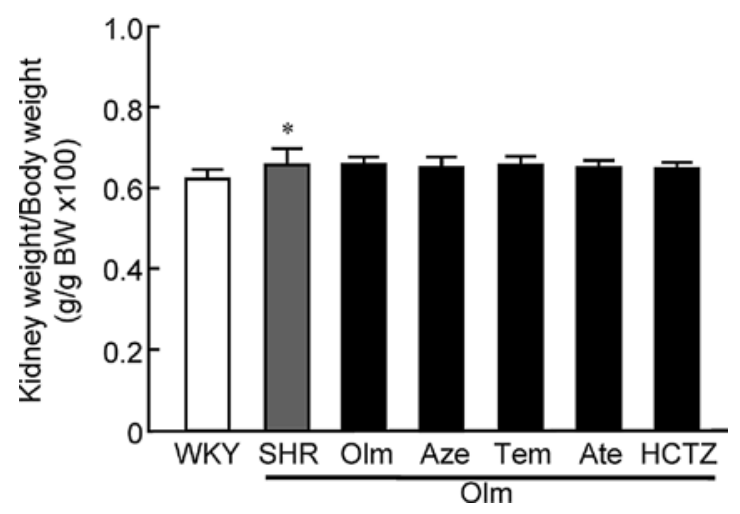

Figure 2. Protective effect of olmesartan (Olm), azelnidipine (Aze), temocapril (Tem), atenolol (Ate) and hydrochlorothiazide (HCTZ) on kidney weight. As one of the phenotypic changes associated with kidney damage, kidney weight was measured in spontaneously hypertensive rats. Values are the mean $\pm \mathrm{SE}$ of 6 animals, expressed as the ratio of kidney weight to body weight. "p $<0.01$ vs. untreated Wistar Kyoto rats.

\section{Discussion}

In clinical studies and experimental models, RAS inhibition has been shown to improve endothelial dysfunction and fibrinolytic activity, and to decrease vascular inflammation and oxidative stress (13-17). Moreover, in clinical trials, RAS 
A.

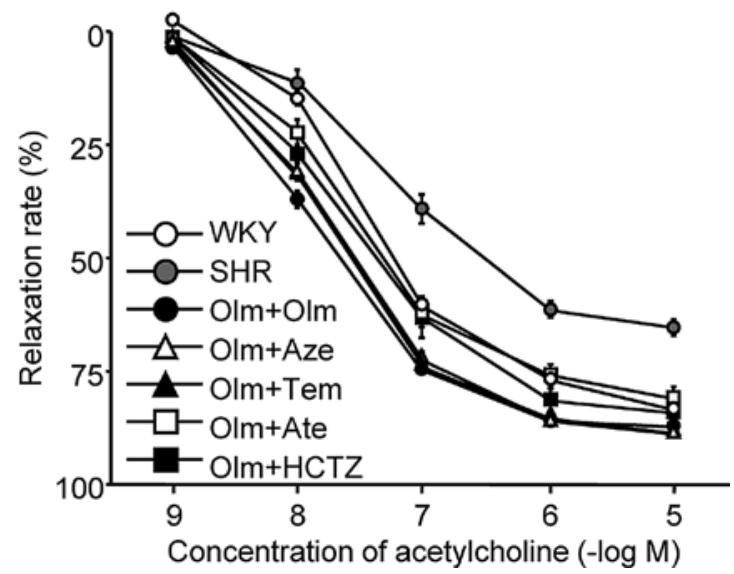

B.

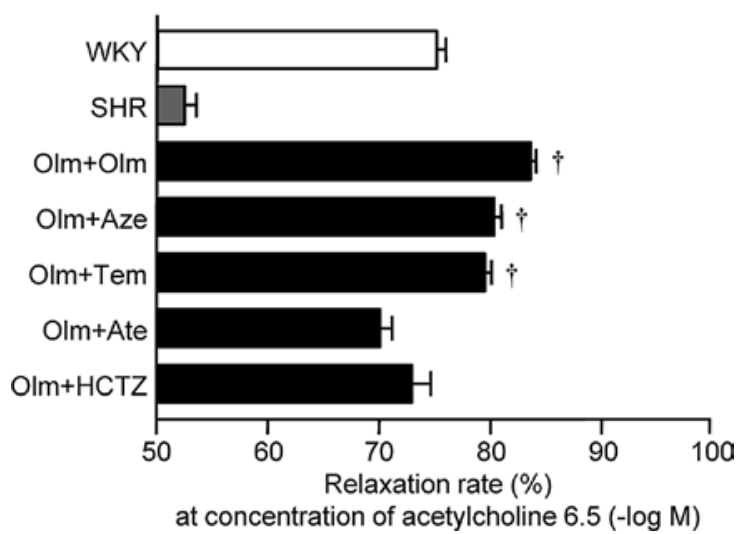

Figure 3. Vasodilator response of the aorta to acetylcholine 8 weeks after each antihypertensive treatment. Values are expressed as percentages of maximum relaxation $(100 \%)$ induced by $10^{-4} \mathrm{M}$ papaverine. Points and vertical bars represent the mean \pm SE of 6 preparations (A). WKY, Wistar Kyoto rats; SHR, spontaneously hypertensive rats; Olm, olmesartan; Aze, azelnidipine; Tem, temocapril; Ate, atenolol; HCTZ, hydrochlorothiazide. Data shown are at the $10^{-6.5} \mathrm{M}$ concentration of acetylcholine (B). Values are the mean \pm SE of 6 preparations. ${ }^{\dagger}<0.05$ vs. untreated WKY, Olm+Ate and $\mathrm{Olm}+\mathrm{HCTZ}$ rats.

inhibition has been shown to reduce the risk of cardiovascular events and mortality and to demonstrate benefits for patients with left ventricular hypertrophy, stroke, heart failure and nondiabetic and diabetic renal diseases (18-21). RAS mediates adaptive and maladaptive responses to cell and tissue injuries, and thereby plays a central role in the pathophysiology of cardiovascular and renal disease through its main effecter, angiotensin (Ang) II (22). The Ang II type $1\left(\mathrm{AT}_{1}\right)$ receptor mediates numerous deleterious effects of Ang II, including vasoconstriction, sympathetic nervous system activation, smooth muscle cell growth and proliferation, vascular inflammation, generation of reactive oxygen species and endothelial dysfunction (23). ARBs counteract the effects of Ang II via distinct pathways by selectively antagonizing all $\mathrm{AT}_{1}$ receptor effects and stimulating $\mathrm{AT}_{2}$ receptors. This may counteract the negative effects of $\mathrm{AT}_{1}$. Based on extensive evidence, ARBs are considered the essential component for the treatment of patients with hypertension and heart failure, diabetes, stroke or chronic kidney disease $(6,7)$.
Hypertension is the most commonly diagnosed disease worldwide. Despite concerted efforts, BP remains poorly controlled, particularly in high risk populations. The most recent age-adjusted estimates show that BP control increased by up to approximately $60 \%$ in treated patients (24). However, BP control was only $30 \%$ in hypertensive patients overall, based on targets for patients with uncomplicated hypertension $(<140 / 90 \mathrm{mmHg})(25)$. It is critical that clinicians worldwide focus on achieving recommended target BP values in these patients. One solution is the use of combination therapy. In terms of efficacy, using two complementary antihypertensive agents in combination consistently results in greater efficacy than high-dose monotherapy. However, it is still unclear which combination or high-dose monotherapy is best from the point of view of organ protection. The present study aimed to elucidate this issue.

We measured BW, BP and HR, and examined heart and kidney weights and endothelial function in seven groups of rats. ARB monotherapy in the first 4 weeks significantly reduced $\mathrm{BP}$ but not $\mathrm{HR}$. At week 8 after treatment with an ARB plus various antihypertensive agents, BP was further reduced compared to the significantly reduced $\mathrm{BP}$ noted at week 4. However, no differences were observed among the groups. In contrast, at week $8, \mathrm{HR}$ was significantly reduced in only two groups, Olm+Ate and Olm+Aze. It was expected that treatment with $\mathrm{Olm}+$ Ate would reduced HR, as atenolol is known to suppress HR by inhibiting sympathetic nerve activation. In contrast to atenolol, CCBs generally increase HR by sympathetic nerve activation due to a rapid decrease in BP. Our results were consistent with previous reports, which indicate that the CCB used in this study, azelnidipine, suppresses HR (26). In keeping with the activity of CCBs, azelnidipine has been reported to suppress the increase in HR by the activation of sympathetic nerve activity induced by a rapid decrease in BP (27). This suppression may be due to the rate of BP lowering (28), or to the direct inactivation of sympathetic nerve activity (29). Further experiments are needed to clarify this mechanism.

Complications associated with hypertension, including stroke, heart failure and renal failure, are often lethal. End-organ damage, including cardiac hypertrophy and arteriosclerosis, occurs during the early phases of these complications. Thus, the prevention of end-organ damage is crucial in the treatment of hypertension $(30,31)$. Based on this consideration, we examined the effect of various antihypertensive treatments on cardiac hypertrophy. Antihypertensives have been reported to have an effect on cardiac hypertrophy in SHR $(32,33)$. In this study, there were no significant differences between the corrected heart and LV weights; the level of cardiac hypertrophy prevention in the treatment groups was almost the same. This may be due to the fact that, though the reduction of BP is key to preventing cardiac hypertrophy, RAS also plays an important role in its development. As each treatment was based on the same ARB, Olm, the inhibition of RAS was potentially sufficient on its own for the prevention of cardiac hypertrophy in the SHR.

Endothelial cells are known to secrete various substances. Among these are many anti-proliferative factors, including nitric oxide and vascular natriuretic peptides. It has thus been hypothesized that endothelial cells modulate vascular growth 
(34-36). Endothelial dysfunction may therefore promote abnormal vascular growth, leading to end-organ damage. In experimental hypertensive models, the activation of vascular RAS has been reported in blood vessels $(37,38)$. In other words, vascular protective effects may be mediated by the blockade of Ang II. In this study, we observed significant improvements in endothelial function in all the treatment groups (Fig. 2). This may be due to the fact that the groups were all subjected to the same ARB-based treatment, resulting in the suppression of RAS. However, the $\mathrm{Olm}+\mathrm{Olm}$ and Olm+Tem groups showed further significant improvement compared to the Olm+Ate and Olm+HCTZ groups (Fig. 3b). The stronger inhibition of RAS by the addition of an ARB or an ACE inhibitor may therefore induce further improvements. Notably, the Olm+Aze group showed a significant improvement in endothelial function compared to the Olm+Ate and Olm+HCTZ groups. As mentioned above, the activation of RAS may play a role in the development of endothelial dysfunction induced by hypertension. The $\mathrm{AT}_{1}$ receptor has been shown to mediate the overproduction of reactive oxygen species via $\mathrm{NAD}(\mathrm{P}) \mathrm{H}$ oxidase in blood vessels in hypertensive models $(17,39)$, and azelnidipine has been reported to suppress the production of reactive oxygen species (40-44). In the present model, azelnidipine may have exerted this anti-oxidative effect, leading to further significant improvements in endothelial function. Though there are few reports on the anti-oxidative effect of atenolol or hydrochlorothiazide, it may explain the observed difference in the improvement of endothelial function.

The potential of ARBs in the prevention of organ damage has been reported in experimental models and clinical studies. ARBs have been proven to have benefits beyond BP lowering effects. This fact warrants the use of ARBs in clinical practice worldwide. Hypertensive patients undergoing treatment seldom achieve the target BP. Thus, combination therapy based on ARBs is recommended in several guidelines. The second-line choice of therapy is generally a CCB, $\beta$-blocker or diuretic. In special cases, a high dose of an ARB or an ARB+ACE inhibitor is necessary. Due to its prohibitively high cost, this stronger inhibition of RAS is only recommended in diabetic or chronic kidney disease patients. The present study suggests that the protective effect against end-organ damage differs depending on the choice of secondary antihypertensive drug.

In conclusion, combination therapy based on an ARB is effective in reducing blood pressure. Moreover, compared to $\beta$-blockers or diuretics, the CCB azelnidipine, which has unique effects on heart rate and oxidative stress, may be suitable in terms of vascular protection.

\section{Acknowledgements}

The authors thank Ms. Emi Nakazato for technical assistance. This study was partially supported by grants from the Japan Health Sciences Foundation, a Grant-in-Aid from the Ministry of Public Health and Welfare, a Grant-in-Aid for the Development of Innovative Technology, and a Grant-in-Aid from the Japan Society for the Promotion of Science.

\section{References}

1. Lewington S, Clarke R, Qizilbash N, Peto R, Collins R and Prospective Studies Collaboration: Age-specific relevance of usual blood pressure to vascular mortality: a meta-analysis of individual data from one million adults in 61 prospective studies. Lancet 360: 1903-1913, 2002.

2. Staessen JA, Wang JG and Thijis L: Cardiovascular protection and blood pressure reduction: a meta-analysis. Lancet 358: 1305-1315, 2001.

3. Chobanian AV, Bakris GL, Black HR, Cushman WC, Green LA, Izzo JL Jr, Jones DW, Materson BJ, Oparil S, Wright JT Jr, Roccella EJ and the National Committee on Prevention, Detection, Evaluation, and Treatment of High Blood Pressure: The JNC 7 reports. J Am Med Assoc 289: 2560-2574, 2003.

4. Hajjar I and Kotchen TA: Trends in prevalence, awareness, treatment, and control of hypertension in the United States, 1988-2000. J Am Med Assoc 290: 199-206, 2003.

5. Hyman DJ and Pavlik VN: Characteristics of patients with uncontrolled hypertension in the United States. N Engl J Med 345: 479-486, 2001.

6. The Task Force for the Management of Arterial Hypertension of the European Society of Hypertension (ESH) and of the European Society of Cardiology (ESC): 2007 Guidelines for the Management of Arterial Hypertension. J Hypertens 25: 1105-1187, 2007.

7. The Japanese Society of Hypertension: Guidelines for the Management of Hypertension (JSH 2009). Hypertens Res 32: 4-107, 2009.

8. Materson BJ, Reda DJ, Cushman WC, Massie BM, Freis ED, Kochar MS, Hamburger RJ, Fye C, Lakshman R, Gottdiener J, Ramirez EA, Henderson WG and The Department of Veterans Affairs Cooperative Study Group on Antihypertensive Agents: Single-drug therapy for hypertension in men. A comparison of six antihypertensive agents with placebo. N Engl J Med 328: 914-921, 1993.

9. Tomita N, Higaki J, Kaneda Y, Yu H, Morishita R, Mikami H and Ogihara T: Hypertensive rats produced by in vivo introduction of the human renin gene. Circ Res 73: 898-905, 1993.

10. Tomita N, Yamasaki K, Izawa K, Kunugiza Y, Osako MK, Ogihara $\mathrm{T}$ and Morishita R: Improvement of organ damage by a nondepressor dose of imidapril in diabetic spontaneously hypertensive rats. Int J Mol Med 19: 571-579, 2007.

11. Namikoshi T, Tomita N, Satoh M, Haruna Y, Kobayashi S, Komai N, Sasaki T and Kashihara N: Olmesartan ameliorates renovascular injury and oxidative stress in Zucker obese rats enhanced by dietary protein. Am J Hypertens 20: 1085-1091, 2007.

12. Namikoshi T, Satoh M, Tomita N, Haruna Y, Kobayashi S, Komai N, Sasaki T and Kashihara N: Pioglitazone ameliorates endothelial dysfunction in obese rats with nephropathy. Biochem Biophys Res Commun 361: 835-840, 2007.

13. Mancini GB, Henry GC, Macaya C, O'Neill BJ, Pucillo AL, Carere RG, Wargovich TJ, Mudra H, Lüscher TF, Klibaner MI, Haber HE, Uprichard AC, Pepine CJ and Pitt B: Angiotensinconverting enzyme inhibition with quinapril improves endothelial vasomotor dysfunction in patients with coronary artery disease: the TREND (Trial on Reversing Endothelial Dysfunction) Study. Circulation 94: 258-265, 1994.

14. Higashi Y, Sasaki S, Nakagawa K, Ueda T, Yoshimizu A, Kurisu S, Matsuura H, Kajiyama G and Oshima T: A comparison of angiotensin-conv erting enzyme inhibitors, calcium antagonists, beta-blockers and diuretic agents on reactive hyperemia in patients with essential hypertension: a multicentre study. J Am Coll Cardiol 35: 284-291, 2000.

15. Brown NJ, Agirbasli M and Vaugham DE: Comparative effect of angiotensin-converting enzyme inhibition and angiotensin II type 1 receptor antagonism on plasma fibrinolytic balance in humans. Hypertension 34: 285-290, 1999.

16. Sironi L, Gelosa P, Guerrini U, Banfi C, Crippa V, Brioschi M, Gianazza E, Nobili E, Gianella A, de Gasparo M and Tremoli E: Anti-inflammatory effects of AT1 receptor blockade provide end-organ protection in stroke-prone rats independently from pressure fall. J Pharmacol Exp Ther 311: 989-995, 2004.

17. Ogawa $\mathrm{S}$, Mori $\mathrm{T}$, Nako $\mathrm{K}$, Kato $\mathrm{T}$, Takeuchi $\mathrm{K}$ and Ito $\mathrm{S}$ : Angiotensin II type 1 receptor blockers reduce urinary oxidative stress markers in hypertensive diabetic nephropathy. Hypertension 47: 699-705, 2006. 
18. Dahlöf B, Devereux RB, Kjeldsen SE, Julius S, Beevers G, de Faire U, Fyhrquist F, Ibsen H, Kristiansson K, LederballePedersen O, Lindholm LH, Nieminen MS, Omvik P, Oparil S, Wedel H and LIFE Study Group: Cardiovascular morbidity and mortality in the Losartan Intervention For Endpoint Reduction in Hypertension Study (LIFE): a randomized trial against atenolol. Lancet 359: 995-1003, 2002.

19. Schrader J, Luders S, Kulschewski A, Hammersen F, Plate K, Berger J, Zidek W, Dominiak P, Diener HC and MOSES Study Group: Morbidity and mortality after stroke, eprosartan compared with nitrendipine for secondary prevention: principal results of a prospective randomized controlled study (MOSES). Stroke 36: 1218-1226, 2005.

20. Cohn JN and Tognoni G: A randomized trial of the angiotensinreceptor blocker valsartan in chronic heart failure. N Engl J Med 345: 1667-1675, 2001.

21. Lewis EJ, Hunsicker LG, Bain RP and Rohde RD: The effect of angiotensin-converting enzyme inhibition on diabetic nephropathy. N Engl J Med 329: 759-766, 1993.

22. Dzau VJ: Tissue angiotensin and pathobiology of vascular disease: a unifying hypothesis. Hypertension 37: 1047-1052, 2001.

23. Schmieder RE, Hilgers KF, Schlaich MP and Schmidt BM: Renin-angiotensin system and cardiovascular risk. Lancet 369 : 1208-1219, 2007.

24. Ong KL, Cheung BM, Man YB, Lau CP and Lam KS: Prevalence, awareness, treatment and control of hypertension among United States adults 1999-2004. Hypertension 49: 69-75, 2004.

25. Chobanian AV, Bakris GL, Black HR, Cushman WC, Green LA, Izzo JL Jr, Jones DW, Materson BJ, Oparil S, Wright JT Jr, Roccella EJ and Joint National Committee on Prevention, Detection, Evaluation, and Treatment of High Blood Pressure; National Heart, Lung, and Blood Institute; National High Blood Pressure Education Program Coordinating Committee: The Seventh Report of the Joint National Committee on Prevention, Detection, Evaluation, and Treatment of High Blood Pressure. Hypertension 42: 1206-1252, 2003.

26. Yamagishi T: Efficacy of azelnidipine on home blood pressure and pulse rate in patients with essential hypertension: comparison with amlodipine. Hypertens Res 29: 767-773, 2006.

27. Eguchi K, Tomizawa H, Ishikawa J, Hoshide S, Fukuda T, Numao T, Shimada K and Kario K: Effects of new calcium channel blocker, azelnidipine, and amlodipine on baroreflex sensitivity and ambulatory blood pressure. J Cardiovasc Pharmacol 49: 394-400, 2007.

28. Shokoji T, Fujisawa Y, Kiyomoto H, Rahman M, Sun GP, Fan YY, Kimura S, Kohno M, Abe Y and Nishiyama A: Effects of a new calcium channel blocker, azelnidipine, on systemic hemodynamics and renal sympathetic nerve activity in spontaneously hypertensive rats. Hypertens Res 28: 1017-1023, 2005.

29. Nakamoto M, Ohya Y, Sakimi A, Yamazato M and Takishita S: Azelnidipine attenuates cardiovascular and sympathetic response to air-jet stress in genetically hypertensive rats. Hypertens Res 30 : 359-366, 2007.

30. Su DF and Miao CY: Reduction of blood pressure variability: a new strategy for the treatment of hypertension. Trends Pharmacol Sci 26: 388-390, 2005.

31. Parati G, Pomidossi G, Albini F, Malaspina D and Mancia G: Relationship of 24-hour blood pressure mean and variability to severity of target organ damage in hypertension. J Hypertens 5: 93-98, 1987.
32. Asai T, Kushiro T, Fujita H and Kanmatsuse K: Different effects on inhibition of cardiac hypertrophy in spontaneous hypertensive rats by monotherapy and combination therapy of adrenergic receptor antagonists and/or the angiotensin II type 1 receptor blocker under comparable blood pressure reduction. Hypertens Res 28: 79-87, 2005.

33. Xie HH, Zhang XF, Chen YY, Shen FM and Su DF: Synergism of hydrochlorothiazide and nifedipine on blood pressure variability reduction and organ protection in spontaneously hypertensive rats. Hypertens Res 31: 685-691, 2008.

34. Tare M, Parkington HC, Coleman HA, Neild TO and Dusting GJ: Hyperpolarization and relaxation of atrial smooth muscle caused by nitric oxide derived from the endothelium. Nature 346: 69-71, 1990.

35. Suga S, Nakao K, Itoh H, Komatsu Y, Ogawa Y, Hama N and Imura $\mathrm{H}$ : Endothelial production of C-type natriuretic peptide and its marked augmentation by transforming growth factor- $\beta$. Possible existence of 'vascular natriuretic peptide system'. J Clin Invest 90: 1145-1149, 1992.

36. Itoh H, Pratt RE and Dzau VJ: Atrial natriuretic polypeptide inhibits hypertrophy of vascular smooth muscle cells. J Clin Invest 86: 1690-1697, 1990.

37. Okamura T, Miyazaki M, Inagami T and Toda N: Vascular renin angiotensin system in two-kidney, one clip hypertensive rats. Hypertension 8: 560-565, 1986.

38. Matsumoto K, Tomita N, Morishita R, Moriguchi A, Komai N, Aoki M, Matsumoto K, Nakamura T, Higaki J and Ogihara T: Improvement of endothelial dysfunction by Angiotensin II blockade accompanied by induction of vascular hepatocyte growth factor system in diabetic spontaneously hypertensive rats. Heart Vessels 18: 18-25, 2003.

39. Leiter LA and Lewanczuk RZ: Of the renin-angiotensin system and reactive oxygen species: type 2 diabetes and angiotensin II inhibition. Am J Hypertens 18: 121-128, 2005.

40. Lukic-Panin V, Kamiya T, Zhang H, Hayashi T, Tsuchiya A, Sehara Y, Deguchi K, Yamashita T and Abe K: Prevention of neuronal damage by calcium channel blockers with antioxidative effects after transient focal ischemia in rats. Brain Res 1176: 143-150, 2007.

41. Manabe S, Okura T, Fukuoka T and Higaki J: Antioxidative effects of azelnidipine on mesangial cell proliferation induced by highly concentrated insulin. Eur J Pharmacol 567: 252-257, 2007.

42. Koyama Y, Takeishi Y, Takahashi H, Shishido T, Arimoto T, Niizeki T, Harada M, Suzuki S, Kitahara T, Sasaki T and Kubota I: Azelnidipine inhibits $\mathrm{H}_{2} \mathrm{O}_{2}$-induced cell death in neonatal rat cardiomyocytes. Cardiovasc Drugs Ther 21: 69-72, 2007.

43. Yamamoto E, Lai ZF, Yamashita T, Tanaka T, Kataoka K, Tokutomi Y, Ito T, Ogawa H and Kim-Mitsuyama S: Enhancement of cardiac oxidative stress by tachycardia and its critical role in cardiac hypertrophy and fibrosis. J Hypertens 24: 2057-2069, 2006.

44. Shinomiya K, Mizushige K, Fukunaga M, Masugata H, Ohmori K, Kohno M and Senda S: Antioxidant effect of a new calcium antagonist, azelnidipine, in cultured human arterial endothelial cells. J Int Med Res 32: 170-175, 2004. 